\title{
Applications of virtual reality modeling language technology for COVID-19 pandemic
}

\author{
Sun Weining ${ }^{\mathrm{a}, *}$ and Zhao Cheli ${ }^{\mathrm{b}}$ \\ a Inner Mongolia University for the Nationalities Academy of Fine Arts, Tongliao, Inner Mongolia, China \\ ${ }^{\mathrm{b}}$ College of Education, Mongolian State University of Education, Ulaanbaatar, Mongolia
}

\begin{abstract}
During COVID-19 pandemic, researchers have used innovative technologies for fast tracking the development to end this pandemic. Virtual Reality (VR) has offered an imperative role for fighting this pandemic, through audiovisualbased virtual communication. Virtual reality modeling language (VRML), as an international standard of virtual reality, has developed rapidly. VRML expanded the function of script node by introducing Java and script programs written in java script language. This paper presents a VRML method. Libraries and platoons are virtualized to meet the normal use of users. In principle, any text editing system can be used for VRML programming, but some editing systems have few related functions and are not suitable for large-scale VRML Scene Design. The VRML algorithm proposed in this paper can be applied to large buildings. The VRML algorithm proposed in this paper is compared with the traditional algorithm. The VRML algorithm proposed in this paper is superior to the traditional algorithm in the aspects of realism, interactivity, design rationality and execution speed. The practicability of the VRML algorithm is proved. It provides help for people who are inconvenient to go out during the protection period of covid-19.
\end{abstract}

Keywords: Virtual reality modeling language virtual library, virtual volleyball hall, 3D, Internet, system

\section{Introduction}

During COVID-19 pandemic, researchers have used innovative technologies for fast tracking the development to end this pandemic. Virtual Reality (VR) has offered an imperative role for fighting this pandemic, through audiovisual-based virtual communication. VR technology develops a platform to reduce the face to face interaction of doctors with the infected COVID-19 patients. Through live video streaming, it helps to improve surveillance systems on the ongoing situation. Virtual Reality Modeling Language (ISO/IEC 14772-1 : 1997), as an international

\footnotetext{
${ }^{*}$ Corresponding author. Sun Weining, Inner Mongolia University for the Nationalities Academy of Fine Arts, Tongliao 028000, Inner Mongolia, China. E-mail: miweiba@163.com.
}

standard of virtual reality, has been developing rapidly. VRML was first proposed by Rava Raggett of HP European Research Laboratory at the first World Wide Web Conference held in Geneva, Switzerland, in May 1994 [1, 2]. In the near future, Silicon Graphics Inc, was mainly used by Mark Pesce and others, SGI's Open Inventor ASCII file format formulates VRML standard. VRML is a language technology to create virtual reality environment on the Web [3]. It uses the high technology in the development of computer to effectively build a virtual reality world with two-dimensional, three-dimensional, text and multimedia materials, so that participants can get a similar feeling with the real world. VRML can be used to construct a variety of virtual scenes [4-6], For example, venues, parks, mountains, sky, and earth, you can also add sound and video to 
virtual scenes to make them more vivid and closer to reality [7].

The access mode based on client/server mode. As a workstation, the server is responsible for coordinating the vast majority of simulation activities, providing VRML files and resources (2D, 3D, text and multimedia materials, etc.), and maintaining the state of all virtual objects in the environment. The client downloads the required files through the Web, runs the client process, and manages the user avatar, Use input/output tools for interaction, and complete scene rendering and system interaction in real time through VRML browser of local platform. Design and extensibility of distributed environment. VRML files have built-in mechanism to support multiple distributed files, and also provide external prototype reference mechanism, anchor mechanism, scripting language and other mechanisms. The descriptive language of ASCII text format. VRML is the same as HTML. It can be used in all kinds of platforms. Enhanced static scene. Some new function nodes of VRML can enhance the reality of 3D static scene. For example, Fog node can also produce realistic atmospheric effect of environment atomization. Interactivity and animation. VRML contact sensor, environment sensor, perception sensor and collision sensor can be used for real-time interactive simulation of 3D modeling. Through the sound node, VRML can set the spatial attributes of sound, such as the size of Sound, the position of sound source, the direction of propagation, etc., so as to show the three-dimensional sound effect with different height and distance. Java and Java Script support. VRML extends the function of Script node by introducing script programs written in Java and Java Script language.

\section{Overall design of virtual library}

VRML is more and more widely used in social life, which constantly changes people's daily life. In recent years, virtual library also began to rise. The virtual library expands the traditional library from two-dimensional to three-dimensional, presenting the general picture of the library more vividly, making it convenient for users to browse in real time through the network in different places, as if they are in the scene. Therefore, the virtual library should meet the following requirements:

- It can truly display the overall structure and external framework of the library, including the appearance, shape, geographical location, surrounding environment, etc;

- It can vividly display the internal structure of the library, including rooms with various functions, desks, chairs, bookshelves and books of each library, etc;

- It can realize various forms of roaming. In the process of roaming, it can move tables and chairs, flip books, open doors and windows, control switches, etc., and realize simple interactive functions;

- It can browse online, the model rendering speed is faster and the browsing smoothness is higher

In order to meet the above requirements, the virtual library is divided into two parts: outside and inside. Outside the library includes the overall appearance and surrounding environment of the library, and inside the library includes various office space, desks, chairs, books and other objects. Because the objects of the virtual library are organized together through the relationship of space relative position, it is necessary to first establish an object as a reference object called other objects After analysis, this paper selects the road in front of the library as the reference, according to the principle of from outside to inside, from bottom to top, from left to right, to form the scene structure of the virtual library as shown in Fig. 1.

\subsection{Development tools and processes}

Although VRML syntax is simple, it is quite tedious to write code manually. Especially for modeling irregular modeling objects, it is very difficult. In the actual development process, a variety of virtual reality software needs to be used, following the development process shown in Fig. 2.

The specific process is as follows: first, use professional 3D modeling software (such as: 3DS Max.Maya). The 3D model of solid object is established. After texture mapping and rendering, a single object model is formed. Secondly, the model is imported into visual editing software (such as Internet Space Builder and Cosmo Worlds), a single model is placed in a proper position and an overall scene is established by copying and rotating [8]. Thirdly, a program written in Java or Java Script is used to expand the function of VRML and add interaction for the scene. Then, VRML model files are compressed and optimized in text editing software (such as Vrmlpad) to improve the overall performance of 


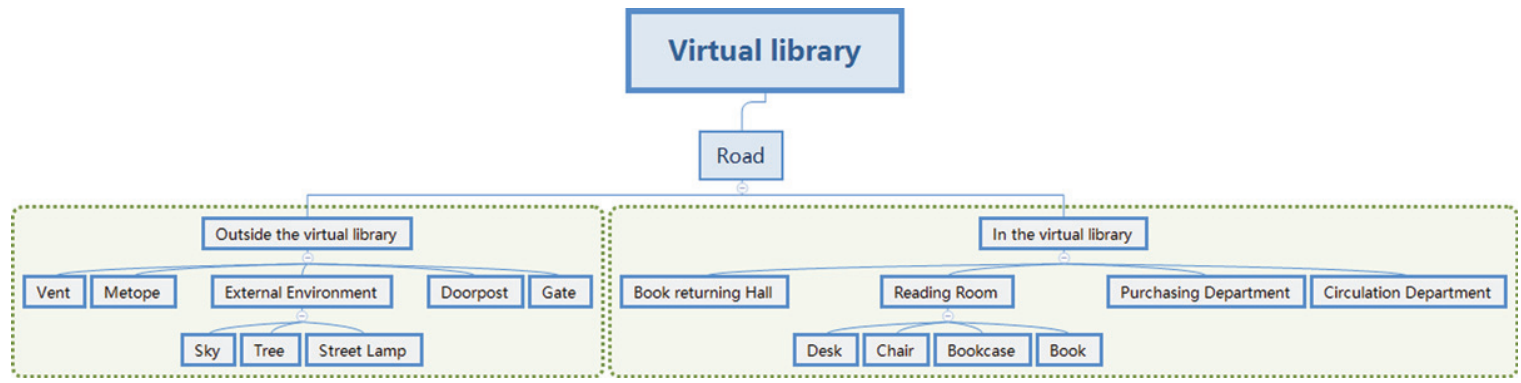

Fig. 1. scene structure of Virtual Library.

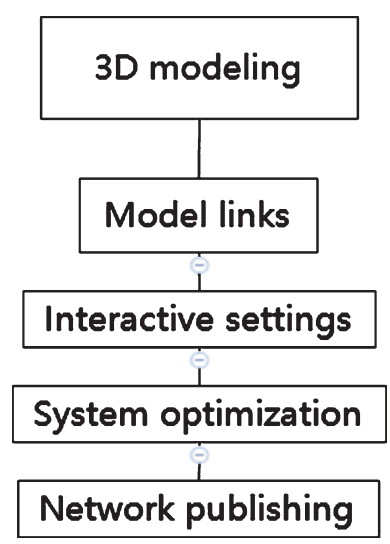

Fig. 2. development process of Virtual Library.

the system; Finally, the generated scene file is inserted into the web page and published to the network [9-11].

The development tools used in this paper are: Based on VRML, using 3D Studio MAX as the main modeling tool, using SGI's visual editing tool Cosmo Worlds to inline the model, using VRML script editing software Vrmlpad to optimize the code, adding interactive scripts, and using Cortona VRML browser to preview the effect [12].

\subsection{Three dimensional scene construction of virtual library}

The establishment of three-dimensional model is the foundation of realizing virtual library. In the modeling, the accuracy requirements of the application requirements for the model, the efficiency requirements of the construction period for the modeling, and the cost requirements of the construction funds for the investment determine the modeling method. In this paper, three-dimensional modeling software is used to establish the model framework, and tex- ture mapping is widely used to reduce the complexity of the model, so as to achieve efficient construction purpose of module.

The basic data includes the library's plane structure chart and a large number of material texture data.

The plan structure drawing refers to the plan drawing during the library construction. The plan structure drawing is simplified and modified by Auto CAD, and then imported into 3DS MAX for modeling. The plan design drawing is the base drawing of modeling, which determines the specific orientation, size and location of each building venue $[13,14]$.

The acquisition of texture materials is mainly through field shooting, and then the collected photos are processed to facilitate the use of maps. Photo processing needs to use image processing software (such as photoshop) $[15,16]$. In order to facilitate the later stage of LOD (Levels of Detail) scheduling, each texture image is generated into three versions of blur, common and clear at the same time, which are stored in three different texture databases.

In order to facilitate the integration and fusion of the model, the plane coordinate consistent with the reality and the same length unit should be used in the modeling. The establishment of the three-dimensional model includes two steps: model structure design and surface attribute configuration.

The overall outline model of the library. Based on the engineering drawings, first draw the CAD plan of the library with Auto CAD, then import it into 3DS MAX, form the building height with the stretching method, and then use the shell command to increase the wall thickness, so as to establish the outline model of the library [17]. This method of designing the outline according to the plan mainly uses the Extrude command in 3DS MAX, which is simple in modeling and high in efficiency.

Library wall facilities model. Wall facilities mainly include windows, vents, gates, columns, etc. the main set of window modeling uses the Extrude command to 


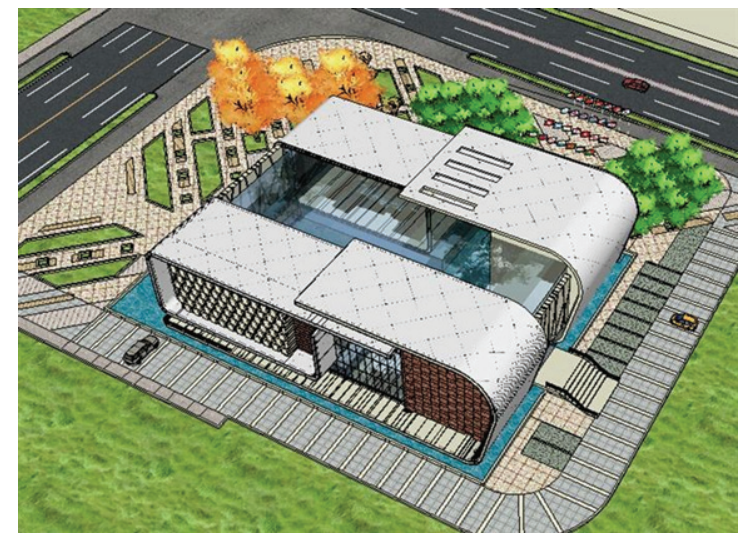

Fig. 3. Peripheral model of Virtual Library.

extrude on the wall to form holes. The vent modeling mainly uses the difference set command of Boolean tool to subtract the length of the wall, Draw the vent. First use the Boolean command to get the rectangular cavity for the door modeling, and then use the capture tool to capture the cavity plane to make the frame of the door. Directly build four cuboids for the column modeling, and put them in the corresponding positions. The completed library peripheral model is shown in Fig. 3.

Model of objects in the library. Library interior object model includes bookcase, book, desk, chair, etc. Bookcase and book model can be directly completed by drawing cuboids. The model of desk and chair needs to draw the model of each part first (the model of desk includes two parts of desk top and desk leg, the model of chair includes three parts of chair frame, cushion and cushion), and then it is composed by combined command to complete the model establishment. The completed model of bookcase, book, desk and chair is shown in Figs. 4-7.

In scene modeling, the reasonable use of texture and material to replace the expression of geometric details of 3D model can not only reduce the modeling workload of 3D model, but also keep the authenticity and fidelity of the model.

Mapping is to cover the material pictures on the model, so that the model is closer to reality. The following is a brief introduction to the basic mapping method, taking the floor given ceramic tile material as an example [18-21]:

Step 1: select the floor, select the building material in the material editor, and drag the picture of a tile to the blank of the diffuse map in the picture library;

Step 2: click the picture in the window, click the diffuse map, and change the number of tiles to 4

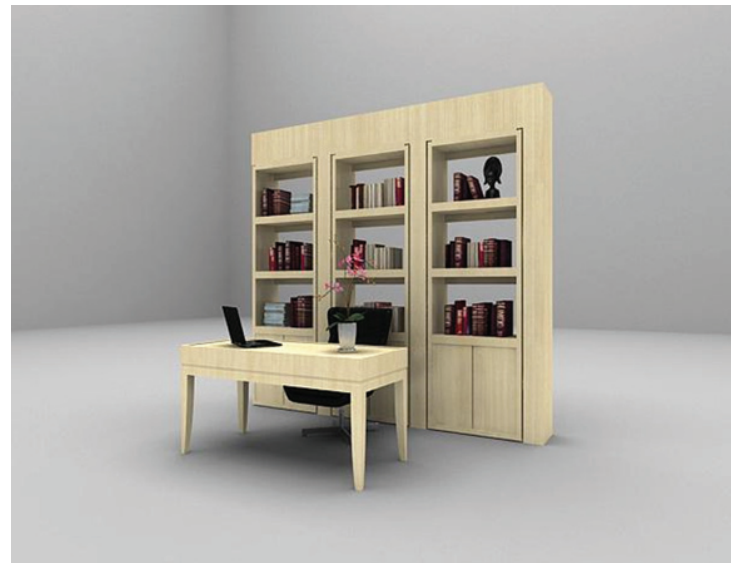

Fig. 4. The bookcase model.

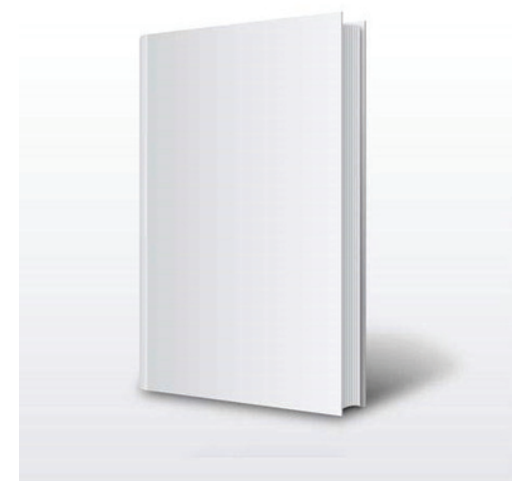

Fig. 5. The book model.

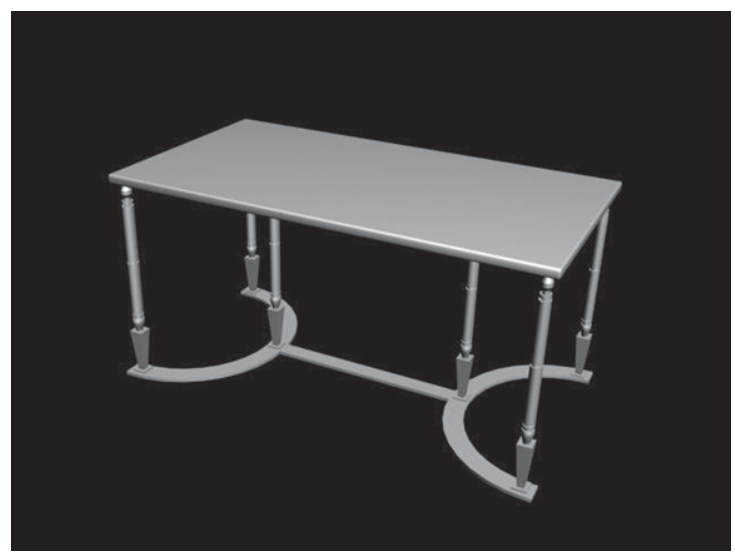

Fig. 6. The desk model.

* 4 . Because the floor is an irregular figure, the map cannot be displayed at this time, so you need to enter the modifier drop-down menu, enter the UV 


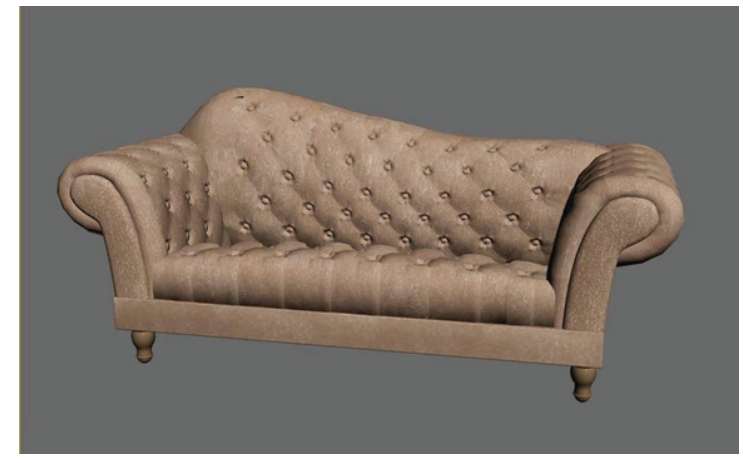

Fig. 7. The chair model.

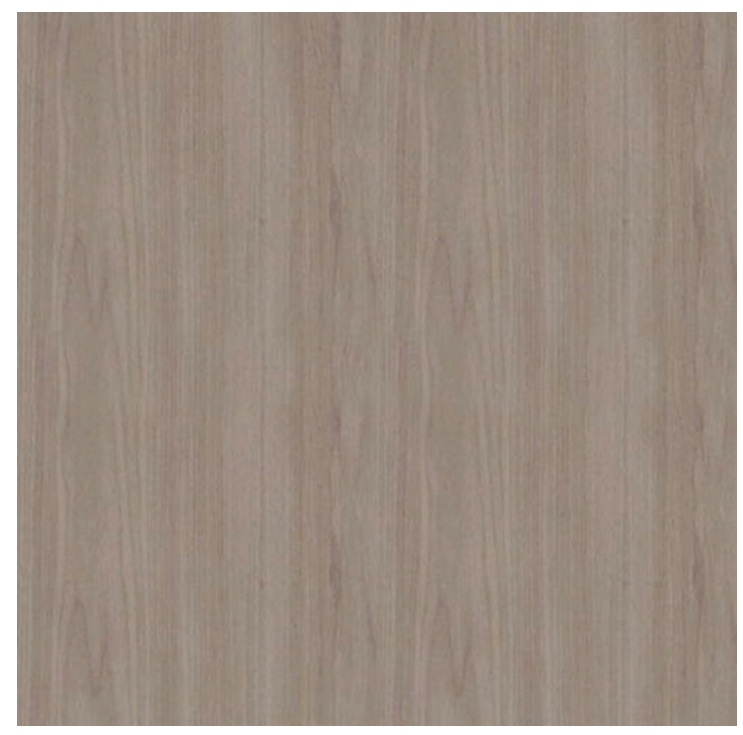

Fig. 8. Floor material adjustment.

coordinate, and then select UVW map to complete the floor pasting, the effect is shown in Fig. 8.

Using the same method, the library exterior wall, interior wall, bookshelf, table and chair models are mapped and simply rendered.

There are also some special environment objects around the library, such as trees, street lights and sky. If these special environment objects are modeled by three-dimensional modeling software, it will take a lot of time and produce a lot of data. Therefore, this paper uses transparent single-sided technology to solve the modeling problem of trees, street lights and flowers. At the same time, it uses opaque single-sided technology to build the sky box.

Transparent single-sided technology refers to the use of image processing software to transparently process the collected texture materials, delete the

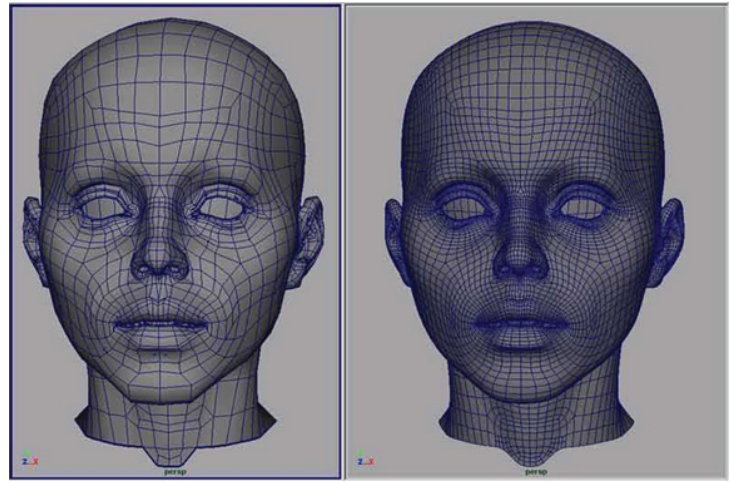

Fig. 9. The modeling the head of a character.

background unrelated to the appearance of the object, and then import it into the modeling software to directly map. This kind of texture is directly attached to the upper layer of other models, which will not block the lower layer of the model, thus forming a three-dimensional effect on the perspective.

\subsection{Fast scheduling of virtual library}

There are many object models in virtual library, so it is not necessary to transfer in all object models during browsing. Therefore, this paper uses the scheduling algorithm based on theVisibility Sensor to schedule only the models that are about to enter the view range, and to eliminate the models that disappear in the view range, which is summarized as "add when visible, remove when invisible". Firstly, the field of view is simplified into a sector. If the objects in the sector are visible, they will be displayed in the VRML scene. If the objects outside the sector are invisible, they need to be removed from the VRML scene. The basic principle is shown in Fig. 9.

When the view area changes, if there is an object in the view area, it will be called into the display; if there is an object out of the view area, it will be eliminated. In this way, the number of buildings entering the view area will be as small as possible to achieve the purpose of fast browsing.

count $=$ BUILDING NUM$_{-} / / / B U I L D I N G_{-}$Num is the number of buildings.

If (the position of the viewpoint moves and the visual field rotates)

\{

for $(j=0 ; j<$ count $; i++)$

$\{/ /$ the $j$-th building is visible

If (the jth building is in the current sector view) 


\section{If (the j-th building was not originally in the sector} view)

\{add the j-th building to the scene; $\}$

//Building J invisible

else if (the first building was originally in the sector view)

$\{$ remove the $j$-th building from the scene; $\}$

\}

According to the distance between the object and the point of view, different precision models are transferred to the models that enter the field of view. In the texture and material processing stage, each texture generates three versions of blur, common and clear at the same time. After mapping different precision textures, different precision models will be generated. The basic idea of LOD is to use a group (usually 3-5) of different precision models For the model of degree, different precision models are called according to the preset distance threshold during browsing. When the distance is long, fuzzy models are called, and when the distance is short, clear models are called, so as to speed up the rendering speed of the scene. The basic syntax of LOD in VRML is as follows:

\section{$L O D\{$ \\ Level [the highest level of detail, the second highest level,...] \\ exposedField MFNode \\ center\#LOD the position of the modeling center SFVec $3 f$ \\ range [distance $d 1$, distance $d 2, \ldots$ ]MFFloat \}}

When the value of range domain is used to judge how far the viewpoint is from the object, the object model arranged in level is called (from fine to coarse). The distance threshold $\mathrm{d}$ here can be calculated according to the method in the literature:

$$
\begin{gathered}
s=\frac{\text { rootsize } \times \sqrt{3}}{2^{\text {depth }}} \\
d=\frac{s \times(100 \times 2 \times \tan \partial / 2)}{\text { errorrange }}
\end{gathered}
$$

Rootsize is the size of the bounding box of the object cube, depth is the level, and errorrange is the size of the error range given as a percentage. The advantage of LOD is to simplify the calculation in the preprocessing process, which can reduce the calculation cost of real-time rendering. In this paper, the idea of LOD is used to schedule the object models with different precision according to the distance of the view point for the objects entering the view point range.

\section{Design of virtual volleyball venue based on VRML}

\subsection{Design of volleyball hall based on VRML}

In principle, any kind of text editing system can be used for VRML programming design, but some editing systems have few related functions and are not suitable for large-scale VRML scene design. More professional VRML editing systems include Internet 3D Space Builder, Cosmo Worlds, VrmlPad, etc. However, in real design and production, 3D animation software (such as Maya, etc.) is usually used, $3 \mathrm{dsmax}$, etc. for VRML virtual scene design, of course, it is necessary to install plug-ins for 3D animation software. 3D animation software has some disadvantages more or less, so it is necessary to find a text editor to optimize the code. Using VrmlPad text editor can shorten the code writing time and improve the work efficiency.

VRML technology can build a similar environment with real volleyball venues, and can build a variety of virtual models with rich shapes, materials, and detail surfaces to truly represent the situation of volleyball venues. Students can use computer screen as a window to observe virtual volleyball venues, and fully interact with virtual volleyball venues through input devices such as mouse and keyboard The direction keys on the keyboard control the characters in the virtual scene, You can choose different paths to visit the volleyball venues, and click (or virtual role goes to the corresponding position) the volleyball venues, volleyball nets and other related sports facilities in the virtual scene to obtain their physical data, so as to deepen the grasp of the basic theoretical knowledge of volleyball and make learning more lively.

For the modeling of the virtual character, due to the complexity of the virtual character model, 3D animation software (such as Maya, 3DS MAX, etc.) is usually used for modeling, and VRML format files are generated by installing the corresponding plugins. The Polygons tool in Maya can be used for the modeling of the character head (see Fig. 9), The body of the character can be drawn using the EP Curve tool in Maya (see Fig. 10). The limbs of the character are modeled by the cylinder in the polygons tool 


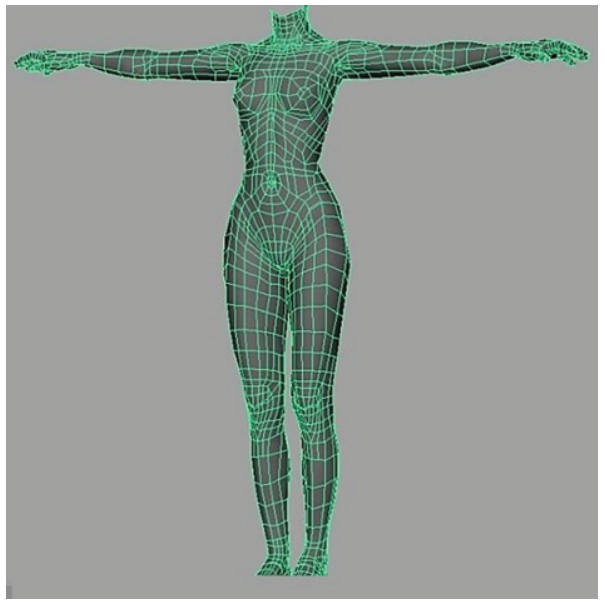

Fig. 10. The drawing of figure body.

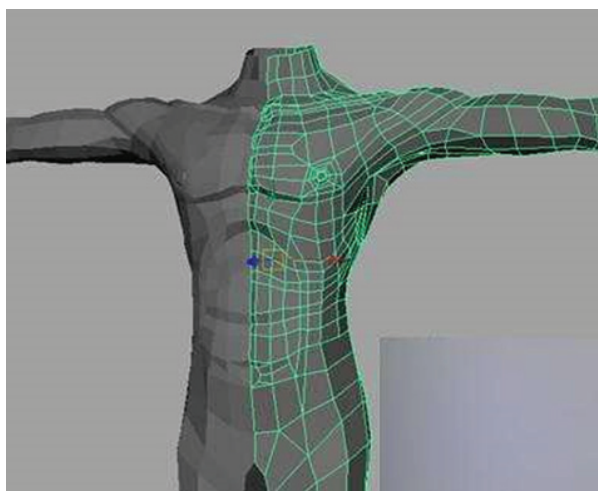

Fig. 11. The modeling the upper limbs of characters.

(see Fig. 11). The hands and feet of the character are modeled by the cube in the polygons tool which is shown in Fig. 12.

In the animation mode of Maya, through a series of commands such as Skeleton, a skeleton is made to exert influence on the skin, and then control the persona through internal commands.

Maya's animation function is relatively powerful, and it has certain advantages in making simulation. It can completely create a simulated character and complete complex actions in any set environment.

The changes of persona's expression are various. In the production, we should avoid the sameness, but we should also make it according to the characteristics of some animations. We can use Blend Shape to make expression animation. Compared with Maya, motion builder is simpler and easier to control in animation.

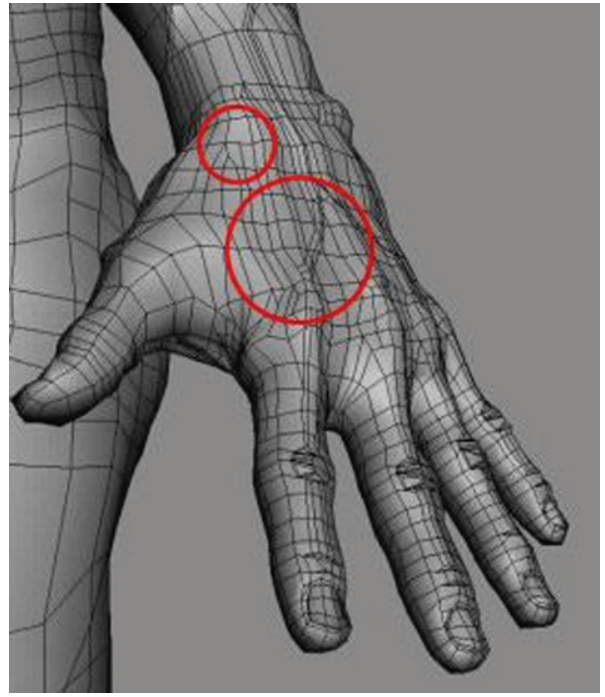

Fig. 12. The hand modeling.

Table 1

The array of virtual volleyball net

\begin{tabular}{lccccc}
$\mathrm{f}$ & \multicolumn{7}{l}{ The array of virtual volleyball net } \\
$\begin{array}{l}\text { fName } \\
\mathrm{f}\end{array}$ & $\begin{array}{c}\text { Net } \\
\text { height }\end{array}$ & $\begin{array}{c}\text { Net } \\
\text { length }\end{array}$ & $\begin{array}{c}\text { Net } \\
\text { width }\end{array}$ & Mesh & $\begin{array}{c}\text { Top } \\
\text { edge } \\
\text { height }\end{array}$ \\
$\begin{array}{l}\text { f Volleyball } \\
\text { net(man) } \\
\text { fVolleyball } \\
\text { net(woman) }\end{array}$ & 243 & 950 & 100 & $10 \times 10$ & 5 \\
\hline
\end{tabular}

\subsection{The application of VRML in VT}

The display technology of physical information of virtual volleyball stadium facilities can be made by using VT (Virtools) software. The database of virtual objects is established by using array in VT software. Firstly, the array is established. When adding columns in the array, pay attention to selecting the type of this field. There are five types of integer type and floating-point type, string type, object type, parameter type, general name is set as string type, weight and size can be set as floating point type, etc. which is shown in Table 1.

After the array is established, the data information in the array is called out by obtaining data from the row in BB. For the data output from the row, it is integer type, floating-point type and string type, which can be directly converted and output by using style display, which is shown in Fig. 13 for BB code.

The following aspects should be paid attention to when the virtual role roams in the virtual volleyball venues: first, the control of the virtual role can control 


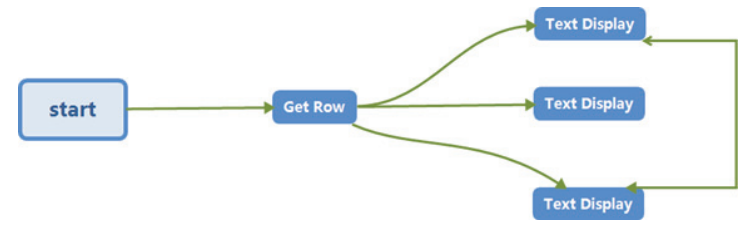

Fig. 13. BB code.

the movement of the virtual role well through the keyboard (such as four direction keys); second, the recognition of the virtual role to the ground, so that the virtual corner color does not fall to the edge of the floor; Then the shadow of virtual role can be divided into three kinds: simple shadow, plane shadow and projection shadow. The simple shadow is too simple to express virtual role vividly. Although the effect of projection shadow is very good, it consumes the performance of the system, so we choose plane shadow in the design process Finally, collision detection between virtual roles and some virtual objects is carried out to prevent penetration between virtual roles and other virtual objects when roaming in venues, so that virtual roles can recognize virtual objects, and collision detection can occur without penetration, which is shown in Fig. 14.

\section{The overall system design of VRML}

\subsection{Design of VRML architecture experience system}

Figure 15 is the modeling roadmap of $3 \mathrm{D}$ virtual building space. The location data of $3 \mathrm{D}$ virtual build-

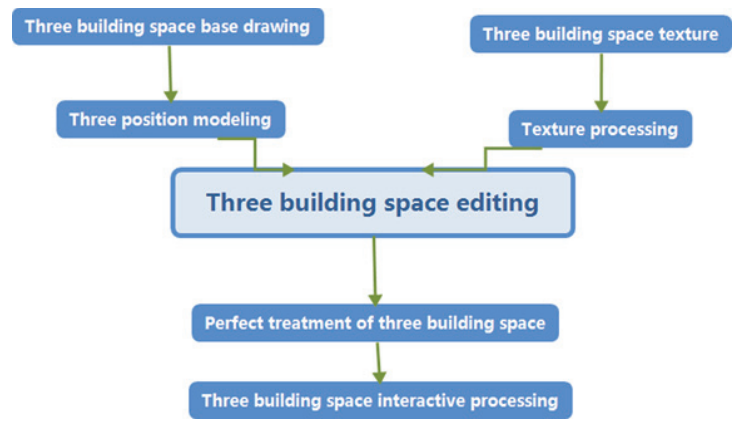

Fig. 15. Modeling route of 3D virtual building space.

ing space modeling is displayed by using 2D map as base map. Using 3 dsmax $3 \mathrm{D}$ virtual modeling program to construct the 3D model of building space and complete the 3D construction of 3D virtual building space. The data of 3D virtual building space model should be consistent with its attribute information and added with texture. The texture can directly show the external characteristics of the entity and environment. After the operation of Photoshop and other software, the 3D virtual building space model is imported. The three-dimensional model of building space integrates form and color through visual operation. Based on digital terrain, all models are built on it, and a complete three-dimensional virtual building space model is built according to its position, angle and proportion.

The set model is imported into the VR-Platform software and the software is used to set the model running window. The effect pictures of interactive $3 \mathrm{D}$ virtual building space experience system is shown in Fig. 16.

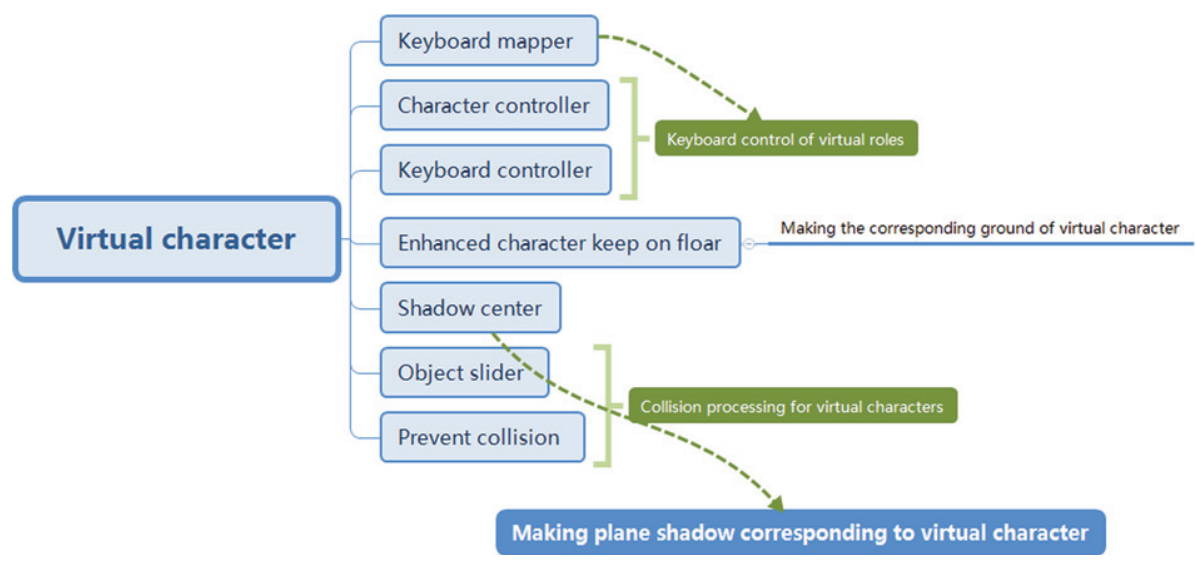

Fig. 14. The part of BB code to realize interaction. 


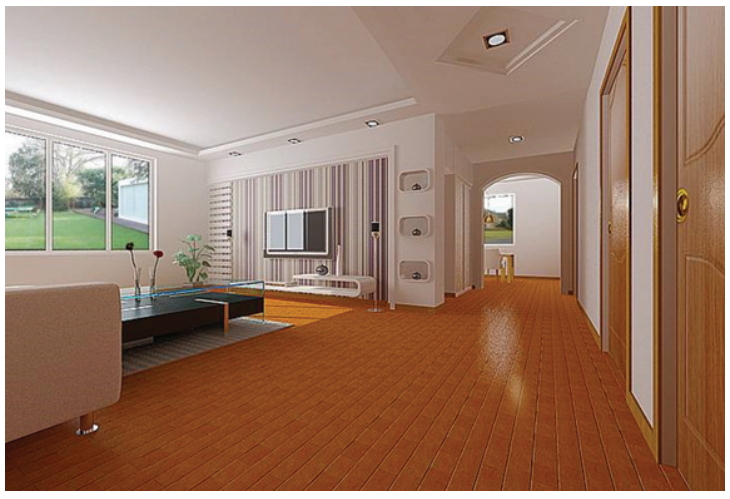

Fig. 16. Effect pictures of interactive 3D virtual building space experience system.

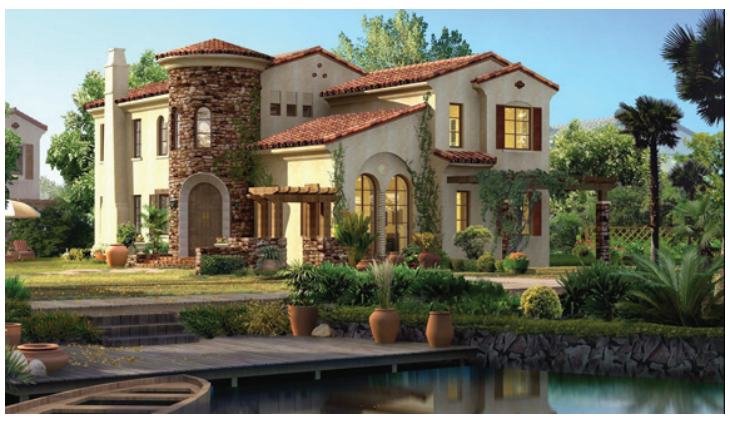

Fig. 17. Effect picture of 3D virtual building space experience.

\subsection{Experimental analysis}

Figure 17 shows the user feedback 3D virtual building space experience rendering. The speed of image presentation is up to one million dots/frame; there is no card sense when calculating the conventional image, and the triangular surface is up to $1 / 14$; the system in this paper can meet the needs of users and reach a high level in operating experience.

The application process of this system is shown in the experiment. First, build the model. According to the classification of the components of the bucket arch, the model can be built as a whole, and the corresponding information is input into the database to complete the modeling. Then the data is sorted out. After building the model. Finally, the model is released. Publish the perfect model to the system, and the interactive display effect of the three-dimensional virtual building space of the Dougong is shown in Fig. 18.

In the experiment, 100 Citizens in a city center were randomly selected and divided into 10 groups.

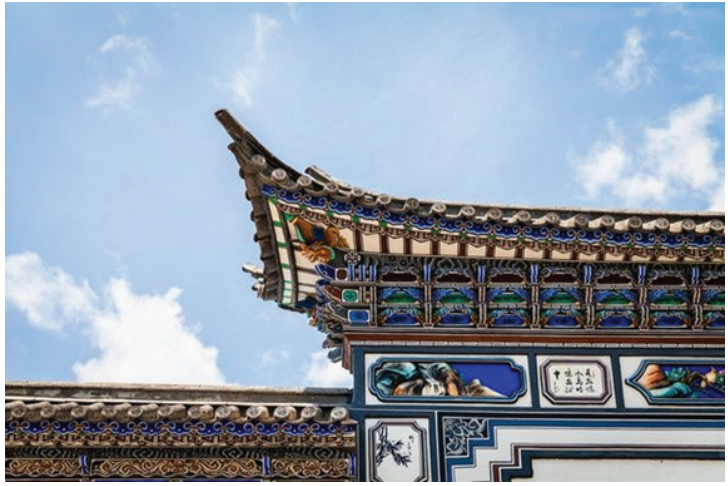

Fig. 18. Interactive display effect pictures for 3D virtual building space of bucket arch.

Table 2

User experience scores of system in this paper

\begin{tabular}{lccccc}
\hline $\begin{array}{l}\text { Group- } \\
\text { ing }\end{array}$ & $\begin{array}{c}\text { Real- } \\
\text { ism }\end{array}$ & $\begin{array}{c}\text { Inter- } \\
\text { activity }\end{array}$ & $\begin{array}{c}\text { Design } \\
\text { rationality }\end{array}$ & $\begin{array}{c}\text { Design } \\
\text { rationality }\end{array}$ & $\begin{array}{c}\text { Execu- } \\
\text { tion } \\
\text { speed }\end{array}$ \\
\hline 1 & 92.36 & 92.07 & 95.63 & 94.62 & 95.72 \\
2 & 93.85 & 96.02 & 94.85 & 93.73 & 96.58 \\
3 & 93.51 & 95.07 & 93.50 & 93.15 & 93.27 \\
4 & 94.73 & 93.71 & 92.60 & 95.22 & 94.45 \\
5 & 92.68 & 94.58 & 93.99 & 95.34 & 95.38 \\
6 & 93.34 & 93.68 & 94.71 & 93.28 & 92.55 \\
7 & 95.17 & 95.68 & 92.83 & 93.64 & 91.99 \\
8 & 93.66 & 92.57 & 93.79 & 92.72 & 92.68 \\
9 & 94.38 & 92.19 & 94.42 & 94.35 & 93.57 \\
10 & 95.62 & 93.23 & 94.07 & 93.63 & 94.42 \\
Average & 93.93 & 94.02 & 94.07 & 93.97 & 94.06 \\
\hline
\end{tabular}

Table 3

User experience scores of system based on VRML

\begin{tabular}{lccccc}
\hline $\begin{array}{l}\text { Group- } \\
\text { ing }\end{array}$ & $\begin{array}{c}\text { Real- } \\
\text { ism }\end{array}$ & $\begin{array}{c}\text { Inter- } \\
\text { activity }\end{array}$ & $\begin{array}{c}\text { Design } \\
\text { rationality }\end{array}$ & $\begin{array}{c}\text { Design } \\
\text { rationality }\end{array}$ & $\begin{array}{c}\text { Execu- } \\
\text { tion } \\
\text { speed }\end{array}$ \\
\hline 1 & 86.75 & 87.36 & 84.26 & 87.16 & 84.16 \\
2 & 85.69 & 85.27 & 85.69 & 85.57 & 85.56 \\
3 & 87.25 & 83.96 & 87.21 & 83.29 & 86.19 \\
4 & 86.64 & 84.72 & 85.27 & 85.65 & 82.36 \\
5 & 85.34 & 85.53 & 86.15 & 84.76 & 84.46 \\
6 & 84.97 & 86.42 & 86.33 & 84.18 & 83.69 \\
7 & 82.88 & 87.28 & 85.27 & 85.22 & 84.17 \\
8 & 84.83 & 83.97 & 87.55 & 86.65 & 85.36 \\
9 & 86.65 & 85.51 & 86.75 & 84.39 & 84.18 \\
10 & 87.46 & 87.28 & 85.92 & 85.26 & 86.67 \\
Average & 85.87 & 85.73 & 86.04 & 85.21 & 84.69 \\
\hline
\end{tabular}

Using the system in this paper, the experience system based on VRML and the experience system based on perception, the experience of a three-dimensional 
Table 4

User experience scores of system based on perception

\begin{tabular}{lccccc}
\hline $\begin{array}{l}\text { Group- } \\
\text { ing }\end{array}$ & $\begin{array}{c}\text { Group- } \\
\text { ing }\end{array}$ & $\begin{array}{c}\text { Group- } \\
\text { ing }\end{array}$ & $\begin{array}{c}\text { Group- } \\
\text { ing }\end{array}$ & $\begin{array}{c}\text { Group- } \\
\text { ing }\end{array}$ & $\begin{array}{c}\text { Group- } \\
\text { ing }\end{array}$ \\
\hline 1 & 89.65 & 83.21 & 85.35 & 85.36 & 82.16 \\
2 & 82.33 & 85.53 & 82.88 & 83.56 & 83.56 \\
3 & 82.15 & 85.42 & 85.41 & 84.21 & 84.19 \\
4 & 83.03 & 87.11 & 84.27 & 83.65 & 86.36 \\
5 & 85.18 & 85.52 & 85.12 & 85.26 & 83.46 \\
6 & 84.05 & 83.04 & 85.31 & 83.38 & 84.69 \\
7 & 82.36 & 84.17 & 97.25 & 84.42 & 85.13 \\
8 & 84.82 & 85.53 & $/ 8.36$ & 86.65 & 82.35 \\
9 & 86.55 & 86.28 & 84.25 & 85.29 & 83.19 \\
10 & 87.12 & 87.16 & 83.92 & 83.26 & 86.67 \\
Average & 84.72 & 85.50 & 84.71 & 84.60 & 84.18 \\
\hline
\end{tabular}

virtual building space in a city center was scored. See Tables 2 to 4 for the score results.

From Tables 2 to 4, it can be seen that the average scores of user experience of building space in this system are above 90, while the average scores of other two three-dimensional virtual building space experience systems are about 85 , which fully shows that this system is superior to other two traditional systems in user experience, and verifies that this system has strong sense of reality, strong interaction and other advantages, Good user experience performance.

\section{Conclusions}

During the period of covid-19, a virtual library and a virtual volleyball center were established by using VRML technology. It is not only feasible, but also convenient to operate. Let people use it during the epidemic prevention. The design modeling method is mainly based on the following principles: first, programming, using professional VRML editing system, mainly using three-dimensional animation software; second, building three-dimensional model, building three-dimensional effect according to the method, finally, and the virtual space experience system has been continuously optimized and improved.

\section{Acknowledgment}

This paper is supported by science research foundation of Inner Mongolia University for nationalities, project name: Digital Transformation Research of Horqin print, Project No.: NMDYB18059.

\section{References}

[1] Brutzman, Don, The virtual reality modeling language and java, Communications of the ACM 41(6) (1998), 57-64.

[2] J.B. Thurmond, P.A. Drzewiecki and X. Xu, Building simple multiscale visualizations of outcrop geology using virtual reality modeling language (VRML), Computers \& Geosciences 31(7) (2005), 913-919.

[3] S. Grunwald, Soil landscape models at different scales portrayed in virtual reality modeling language, Soil Sci (2000), 165.

[4] H. Wang, K. Zhao and F. Song, Approach to modeling and virtual-reality-based simulation for plant canopy lighting, Chinese Geographical Science 18(4) (2008), 374-381.

[5] L. Zhu, H. Li, W. Liang, et al. A web-based virtual CNC turn-milling system, International Journal of Advanced Manufacturing Technology 78(1-4) (2015), 99-113.

[6] G. Reitmayr, S. Carroll and A. Reitemeyer, DeepMatrix-An open technology based virtual environment system, Visual Computer 15(7/8) (1999), 395-412.

[7] D.O. Kim, H.S. Kang, J.H. Kim, et al. Virtual anatomy and movement of lower extremities using virtual reality modeling language, Journal of Digital Imaging 13(1) (2000), 238-40.

[8] M. Bartsch, M. Clemens, T. Hippler et al. Advanced electromagnetic field visualization using the virtual reality modeling language standard, IEEE Transactions on Magnetics 37(5) (2001), 3604-3607.

[9] K.J.W. Mccaffrey, M. Feely, R. Hennessy et al. Visualization of folding in marble outcrops, Connemara, western Ireland: An application of virtual outcrop technology, Geosphere 4(3) (2008), 588

[10] Marek Moszynski, Andrzej Stepnowski and Krzysztof Bikonis, 3D visualization of marine organism distribution and movement in water column using virtual reality techniques, Journal of the Acoustical Society of America 114(4) (2003), 2301-2301.

[11] M. Castier, Oscar Delgado Cuéllar and F.W. Tavares, Monte Carlo simulation of particle segregation, Powder Technology 97(3) (1998), 200-207.

[12] L. Zhu, H. Li, W. Liang et al. A web-based virtual CNC turn-milling system, International Journal of Advanced Manufacturing Technology 78(1-4) (2014), 99-113.

[13] P. Xin, H. Yu, H. Cheng, et al. Image fusion in craniofacial virtual reality modeling based on CT and 3dMD photogrammetry, Journal of Craniofacial Surgery 24(5) (2013), 1573-1576.

[14] M. Flanders and R.C. Kavanagh, Build-A-Robot: Using virtual reality to visualize the Denavit-Hartenberg parameters, Computer Applications in Engineering Education 23(6) (2015), 846-853.

[15] Tsou, Jennifer C. WARN employment loss defined. (Court Report) (Worker Adjustment and Retraining Notification Act of 1988), Computers in Industry 50(2) (2003), 207-230.

[16] J.S. Liang, A web-based 3D virtual technologies for developing product information framework, The International Journal of Advanced Manufacturing Technology 34(5-6) (2007), 617-630.

[17] T. Yu and X. Zhang, Weili Liang. A web-based virtual system for turn-milling center, International Journal 
of Advanced Manufacturing Technology 67(9-12) (2013), 2395-2409.

[18] B. Damer, K. Marcelo and F. Revi, Nerve garden: germinating biological metaphors in net-based virtual worlds, Kybernetes 32(1/2) (2003), 174-183.

[19] W. Xiangyang, L. Yanbiao and Z. Kaide, Theoretical and experimental study on the fabrication of double fiber bragg gratings, Optical Fiber Technology 3(2) (1997), 189-193.
[20] H.Y. Kan, V.G. Duffy and C.J. Su, An Internet virtual reality collaborative environment for effective product design, Computers in Industry 45(2) (2001), 197-213.

[21] B. Huang and H. Lin, GeoVR: a web-based tool for virtual reality presentation from 2D GIS data, Computers \& Geoences 25(10) (1999), 1167-1175. 